\title{
The Use of Corticosteroids or Tocilizumab in COVID-19 Based on Inflammatory Markers
}

\author{
Manuel Rubio-Rivas, MD PhD ${ }^{\top}$ (i) , José M. Mora-Luján, MD PhD ${ }^{7}$, \\ Abelardo Montero, $M D P h D^{1}$, Josefa Andrea Aguilar García, $M D P h D^{2}$, \\ Manuel Méndez Bailón, $\mathrm{MD}^{3}$, Ana Fernández Cruz, MD PhD ${ }^{4}$, Isabel Oriol, MD PhD ${ }^{5}$, \\ Francisco-Javier Teigell-Muñoz, MD PhD ${ }^{6}$, Beatriz Dendariena Borque, $\mathrm{MD}^{7}$, \\ Andrés De la Peña Fernández, MD PhD ${ }^{8}$, Raquel Fernández González, $M D^{9}$, \\ Ricardo Gil Sánchez, MD PhD ${ }^{10}$, Javier Fernández Fernández, MD ${ }^{17}$, \\ Marta Catalán, $\mathrm{MD}^{12}$, Begoña Cortés-Rodríguez, $\mathrm{MD}^{13}$, Carmen Mella Pérez, $\mathrm{MD}^{14}$, \\ Lorena Montero Rivas, $\mathrm{MD}^{15}$, Rebeca Suárez Fuentetaja, $\mathrm{MD}^{16}$, \\ Jara Eloísa Ternero Vega, $\mathrm{MD}^{17}$, Javier Ena, $\mathrm{MD}^{18}$, \\ Anabel Martin-Urda Díez-Canseco, MD ${ }^{19}$, Cristina Pérez García, $M D^{20}$, \\ José F. Varona, MD PhD'21,22, José Manuel Casas-Rojo, MD PhD 6 , and Jesús Millán \\ Núnez-Cortés, MD PhD ${ }^{23}$ on behalf of the SEMI-COVID-19 Network
}

\begin{abstract}
'Department of Internal Medicine, Bellvitge University Hospital, Bellvitge Biomedical Research Institute-IDIBELL, University of Barcelona, Barcelona, Spain; ${ }^{2}$ Department of Internal Medicine, Costa del Sol Hospital, Marbella, Málaga, Spain; ${ }^{3}$ Department of Internal Medicine, San Carlos University Hospital, Complutense University, Madrid, Spain; ${ }^{4}$ Department of Internal Medicine, Puerta de Hierro University Hospital, Majadahonda, Madrid, Spain; ${ }^{5}$ nfectious Disease Unit, Department of Internal Medicine, Moisès Broggi Hospital, Sant Joan Despí, Barcelona, Spain; ${ }^{6}$ Department of Internal Medicine, Infanta Cristina University Hospital, Parla, Madrid, Spain; ' Department of Internal Medicine, San Pedro Hospital, Logroño, Spain; ${ }^{8}$ Department of Internal Medicine, Son Llàtzer University Hospital, Palma de Mallorca, Spain; ${ }^{9}$ Department of Internal Medicine, Ourense University Hospital, Ourense, Spain; ${ }^{10}$ Department of Internal Medicine, La Fe Hospital, Valencia, Spain; " 'Department of Internal Medicine, Mataró Hospital, Mataró, Barcelona, Spain; ${ }^{12}$ Department of Internal Medicine, Sagunto University Hospital, Sagunto, Valencia, Spain; ${ }^{13}$ Department of Internal Medicine, Alto Guadalquivir Hospital, Andújar, Jaén, Spain; ${ }^{14}$ Department of Internal Medicine, Ferrol Clinical University Hospital, El Ferrol, La Coruña, Spain; ${ }^{15}$ Department of Internal Medicine, Infanta Margarita Hospital, Cabra, Córdoba, Spain; ${ }^{16}$ Department of Internal Medicine, Monforte de Lemos Hospital, Monforte de Lemos, Lugo, Spain; ${ }^{17}$ Department of Internal Medicine, Vírgen del Rocío University Hospital, Sevilla, Spain; ${ }^{18}$ Department of Internal Medicine, Marina Baixa Hospital, Villajoyosa, Alicante, Spain; ${ }^{19}$ Department of Internal Medicine, Palamós Hospital, Palamós, Girona, Spain; ${ }^{20}$ Department of Internal Medicine, Do Salnes Hospital, Vilagarcía de Arousa, Pontevedra, Spain; ${ }^{21}$ Department of Internal Medicine, HM Montepríncipe University Hospital, Madrid, Spain; ${ }^{22}$ Department of Internal Medicine, Infanta Cristina University Hospital, Parla, Madrid, Spain; ${ }^{23}$ Department of Internal Medicine, Gregorio Marañón General University Hospital, Madrid, Spain.
\end{abstract}

BACKGROUND: The inflammatory cascade is the main cause of death in COVID-19 patients. Corticosteroids (CS) and tocilizumab (TCZ) are available to treat this escalation but which patients to administer it remains undefined.

OBJECTIVE: We aimed to evaluate the efficacy of immunosuppressive/anti-inflammatory therapy in COVID-19, based on the degree of inflammation.

DESIGN: A retrospective cohort study with data on patients collected and followed up from March 1st, 2020, to May 1st, 2021, from the nationwide Spanish SEMI-COVID-19 Registry. Patients under treatment with CS vs. those under CS plus TCZ were compared. Effectiveness was explored in 3 risk categories (low, intermediate, high) based on lymphocyte count, C-reactive protein (CRP), lactate dehydrogenase $(\mathrm{LDH})$, ferritin, and D-dimer values.

PATIENTS: A total of 21,962 patients were included in the Registry by May 2021. Of these, 5940 met the inclusion criteria for the present study (5332 were treated with CS and 608 with CS plus TCZ).

Received June 22, 2021

Accepted September 8, 2021

Published online October 18, 2021
MAIN MEASURES: The primary outcome of the study was in-hospital mortality. Secondary outcomes were the composite variable of in-hospital mortality, requirement for high-flow nasal cannula (HFNC), non-invasive mechanical ventilation (NIMV), invasive mechanical ventilation (IMV), or intensive care unit (ICU) admission.

KEY RESULTS: A total of 5940 met the inclusion criteria for the present study (5332 were treated with CS and 608 with CS plus TCZ). No significant differences were observed in either the low/intermediate-risk category $(1.5 \%$ vs. $7.4 \%$, $p=0.175)$ or the high-risk category $(23.1 \%$ vs. $20 \%$, $p=0.223$ ) after propensity score matching. A statistically significant lower mortality was observed in the very high-risk category (31.9\% vs. $23.9 \%, p=0.049$ ).

CONCLUSIONS: The prescription of CS alone or in combination with TCZ should be based on the degrees of inflammation and reserve the CS plus TCZ combination for patients at high and especially very high risk.

KEY WORDS: COVID-19; treatment; corticosteroids; tocilizumab; mortality. 


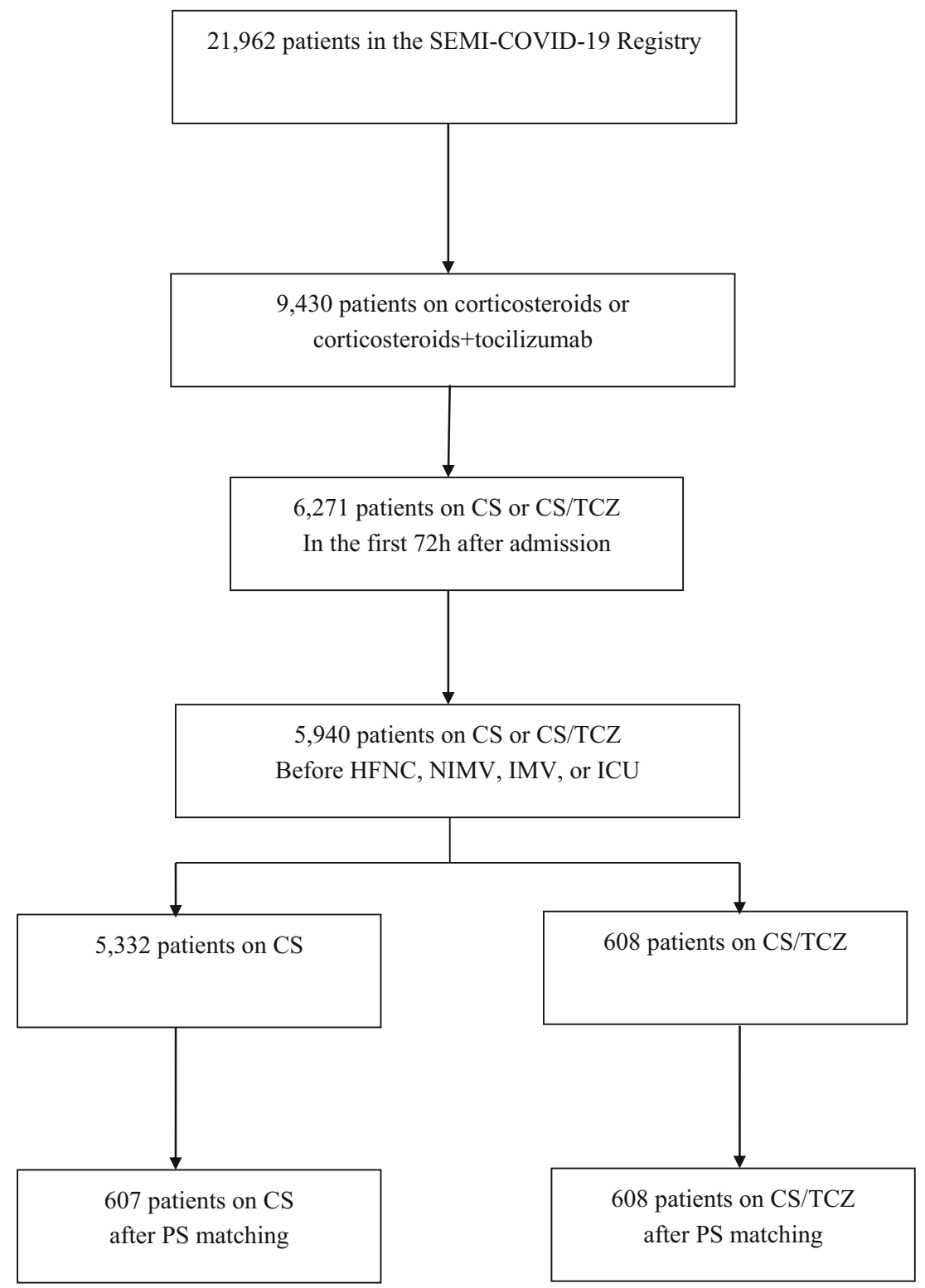

Fig. 1 Flow chart.

Abbreviations
AUC
BMI
COPD
CRP
CS
HFNC
ICU
IMV
IQR
LDH
LMWH
NIMV
OSAS
PCR
PSM
SD

area under the curve
body mass index
chronic obstructive pulmonary disease
C-reactive protein
corticosteroids
high-flow nasal cannula
intensive care unit
invasive mechanical ventilation
interquartile range
lactate dehydrogenase
low-molecular-weight heparin
non-invasive mechanical ventilation
obstructive sleep apnea syndrome
polymerase chain reaction
propensity score matching
standard deviation

SEMI

SOC

TCZ

Spanish Society of Internal Medicine standard of care tocilizumab

J Gen Intern Med 37(1):168-75 DOI: $10.1007 / \mathrm{s} 11606-021-07146-0$

(c) Society of General Internal Medicine 2021

\section{INTRODUCTION}

It has become evident that most of the mortality due to this COVID-19 results from the so-called cytokine storm, ${ }^{1}$ an exaggerated and uncontrolled inflammatory response that frequently leads to death if not aborted. The 2 most commonly 
Table 1 General Data

\begin{tabular}{|c|c|c|c|c|c|c|}
\hline & \multicolumn{3}{|l|}{ All cohort } & \multicolumn{3}{|l|}{ Matched-cohort } \\
\hline & CS & CS+TCZ & $p$ value & CS & $\mathbf{C S}+\mathbf{T C Z}$ & $p$ value \\
\hline$n$ & 5,332 & 608 & & 607 & 608 & \\
\hline Age, median [IQR] & $72.4[59.7-82.7]$ & $63.6[54.8-74.2]$ & $<0.001$ & $63.5[52.4-74]$ & $63.6[54.8-74.2]$ & 0.542 \\
\hline Gender (males), $n(\%)$ & $3,140(58.9)$ & $443(72.9)$ & $<0.001$ & $419(69)$ & $443(72.9)$ & 0.141 \\
\hline Days from onset to admission, median [IQR] & $7[4-9]$ & $7[5-10]$ & $<0.001$ & $7[4-10]$ & $7[5-10]$ & 0.053 \\
\hline BMI, median [IQR] & $28.9[25.7-32.6]$ & $29.1[25.8-32.5]$ & 0.477 & $29.2[25.9-32.8]$ & $29.1[25.8-32.5]$ & 0.967 \\
\hline Race, $n(\%)$ & & & $<0.001$ & & & 0.300 \\
\hline Caucasian & $4,840(90.8)$ & $499(82.1)$ & & $506(83.4)$ & $499(82.1)$ & \\
\hline Black & $35(0.7)$ & $5(0.8)$ & & $8(1.3)$ & $5(0.8)$ & \\
\hline Hispanic & $375(7)$ & $83(13.7)$ & & $70(11.5)$ & $83(13.7)$ & \\
\hline Asian & $17(0.3)$ & $2(0.3)$ & & $7(1.2)$ & $2(0.3)$ & \\
\hline Others & $65(1.2)$ & $19(3.1)$ & & $16(2.6)$ & $19(3.1)$ & \\
\hline Smoking behavior, $n(\%)$ & & & 0.793 & & & 0.505 \\
\hline Never smoker & $3,545(66.5)$ & $409(67.3)$ & & $410(67.5)$ & $409(67.3)$ & \\
\hline Former smoker & $1,527(28.6)$ & $173(28.5)$ & & $163(26.9)$ & $173(28.5)$ & \\
\hline Current smoker & $260(4.9)$ & $26(4.3)$ & & $34(5.6)$ & $26(4.3)$ & \\
\hline Degree of dependency, $n(\%)$ & & & $<0.001$ & & & 0.072 \\
\hline None or mild & $4,169(78.2)$ & $580(95.4)$ & & $579(95.4)$ & $580(95.4)$ & \\
\hline Moderate & $676(12.7)$ & $21(3.5)$ & & $27(4.4)$ & $21(3.5)$ & \\
\hline Severe & $487(9.1)$ & $7(1.2)$ & & $1(0.2)$ & $7(1.2)$ & \\
\hline Arterial hypertension, $n(\%)$ & $3,084(57.8)$ & $297(48.8)$ & $<0.001$ & $304(50.1)$ & $297(48.8)$ & 0.667 \\
\hline Dyslipidemia, $n(\%)$ & $2,255(42.3)$ & $234(38.5)$ & 0.072 & $247(40.7)$ & $234(38.5)$ & 0.432 \\
\hline Diabetes mellitus, $n(\%)$ & $1,218(22.8)$ & $148(24.3)$ & 0.405 & $149(24.5)$ & $148(24.3)$ & 0.934 \\
\hline Ischaemic cardiopathy, $n(\%)$ & $460(8.6)$ & $53(8.7)$ & 0.940 & $62(10.2)$ & $53(8.7)$ & 0.373 \\
\hline Chronic heart failure, $n(\%)$ & $451(8.5)$ & $31(5.1)$ & 0.004 & $32(5.3)$ & $31(5.1)$ & 0.892 \\
\hline Chronic liver disease, $n(\%)$ & $208(3.9)$ & $17(2.8)$ & 0.176 & $26(4.3)$ & $17(2.8)$ & 0.161 \\
\hline Severe chronic renal failure, $n(\%)$ & $413(7.7)$ & $13(2.1)$ & 0.001 & $18(3)$ & $13(2.1)$ & 0.361 \\
\hline Dementia, $n(\%)$ & $605(11.3)$ & $11(1.8)$ & $<0.001$ & $5(0.8)$ & $11(1.8)$ & 0.132 \\
\hline Cancer, $n(\%)$ & $498(9.3)$ & $56(9.2)$ & 0.917 & $61(10)$ & $56(9.2)$ & 0.620 \\
\hline COPD, $n(\%)$ & $522(9.8)$ & $39(6.4)$ & 0.007 & $33(5.4)$ & $39(6.4)$ & 0.470 \\
\hline Asthma, $n(\%)$ & $416(7.8)$ & $44(7.2)$ & 0.621 & $52(8.6)$ & $44(7.2)$ & 0.390 \\
\hline OSAS, $n(\%)$ & $348(6.5)$ & $39(6.4)$ & 0.915 & $35(5.8)$ & $39(6.4)$ & 0.637 \\
\hline Charlson index, median [IQR] & $1[0-2]$ & $0[0-1]$ & $<0.001$ & $1[0-2]$ & $0[0-1]$ & 0.299 \\
\hline
\end{tabular}

BMI body mass index, IQR interquartile range, COPD chronic obstructive pulmonary disease, OSAS obstructive sleep apnea syndrome, CS corticosteroids, CS+TCZ corticosteroids + tocilizumab. Severe chronic renal failure: creatinine $>300 \mathrm{mg} /$ dl or dyalisis

used drugs in the management of COVID-19 are corticosteroids $(\mathrm{CS})^{2,3}$ and tocilizumab (TCZ). ${ }^{3-17}$ While CS have been uniformly found helpful, ${ }^{2,3}$ TCZ efficacy has been mixed. ${ }^{3-17}$ However, most studies have evaluated efficacy based on oxygenation/ventilation of the patients rather than inflammatory markers. Our study aims to evaluate the efficacy of these drugs based on the degree of inflammation. ${ }^{18}$

\section{METHODS}

\section{Study Design, Patient Selection, and Data Collection}

This is a retrospective cohort study with data on patients collected and followed up from March 1st, 2020, to May 1st, 2021, from the nationwide Spanish SEMI-

Table 2 Symptoms and Physical Examination Upon Admission

\begin{tabular}{|c|c|c|c|c|c|c|}
\hline & \multicolumn{3}{|l|}{ All cohort } & \multicolumn{3}{|c|}{ Matched-cohort } \\
\hline & CS & $\mathrm{CS}+\mathrm{TCZ}$ & $p$ value & CS & CS+TCZ & $p$ value \\
\hline Cough, $n(\%)$ & $3677(69)$ & $485(79.8)$ & $<0.001$ & $434(71.5)$ & $485(79.8)$ & 0.001 \\
\hline Arthromyalgias, $n(\%)$ & $1425(26.7)$ & $211(34.7)$ & $<0.001$ & $182(30)$ & $211(34.7)$ & 0.079 \\
\hline Ageusia, $n(\%)$ & $574(10.8)$ & $71(11.7)$ & 0.493 & $88(14.5)$ & $71(11.7)$ & 0.145 \\
\hline Anosmia, $n(\%)$ & $484(9.1)$ & $68(11.2)$ & 0.090 & $69(11.4)$ & $68(11.2)$ & 0.920 \\
\hline Sore throat, $n(\%)$ & $428(8)$ & $72(11.8)$ & 0.001 & $69(11.4)$ & $72(11.8)$ & 0.796 \\
\hline Headache, $n(\%)$ & $608(11.4)$ & $96(15.8)$ & 0.002 & $74(12.2)$ & $96(15.8)$ & 0.071 \\
\hline Fever, $n(\%)$ & $4118(77.2)$ & $523(86)$ & $<0.001$ & $505(83.2)$ & $523(86)$ & 0.173 \\
\hline Dyspnea, $n(\%)$ & $3625(68)$ & $433(71.2)$ & 0.105 & $434(71.5)$ & $433(71.2)$ & 0.913 \\
\hline Diarrhea, $n(\%)$ & $1231(23.1)$ & $181(29.8)$ & $<0.001$ & $163(26.9)$ & $181(29.8)$ & 0.259 \\
\hline Vomiting, $n(\%)$ & $360(6.8)$ & $44(7.2)$ & 0.653 & $42(6.9)$ & $44(7.2)$ & 0.829 \\
\hline Abdominal pain, $n(\%)$ & $285(5.3)$ & $34(5.6)$ & 0.798 & $30(4.9)$ & $34(5.6)$ & 0.612 \\
\hline Heart rate, bpm median [IQR] & $87[76-100]$ & $91[80-104]$ & $<0.001$ & $90[80-101]$ & $91[80-104]$ & 0.079 \\
\hline Respiratory rate $>20 \mathrm{rpm}, n(\%)$ & $2109(39.6)$ & $328(53.9)$ & $<0.001$ & $314(51.7)$ & $328^{2}(53.9)$ & 0.439 \\
\hline
\end{tabular}

IQR interquartile range, CS corticosteroids, CS+TCZ corticosteroids + tocilizumab 
Table 3 Lab Tests Upon Admission

\begin{tabular}{|c|c|c|c|c|c|c|}
\hline & \multicolumn{3}{|l|}{ All cohort } & \multicolumn{3}{|l|}{ Matched-cohort } \\
\hline & CS & CS+TCZ & $p$ value & CS & $\mathrm{CS}+\mathrm{TCZ}$ & $\begin{array}{l}p \\
\text { value }\end{array}$ \\
\hline $\mathrm{PaO} 2 / \mathrm{FiO} 2$, median $[\mathrm{IQR}]$ & $\begin{array}{l}285.7[231.9- \\
338.1]\end{array}$ & 271 [214.3-320.4] & $<0.001$ & $\begin{array}{l}266.7[209.7- \\
319.1]\end{array}$ & 271 [214.3-320.4] & 0.484 \\
\hline $\begin{array}{l}\text { Lymphocytes } \times 10^{6} / 1 \text {, median } \\
\text { [IQR] }\end{array}$ & $900[612.5-1260]$ & $820[600-1120]$ & $<0.001$ & $850[600-1200]$ & $820[600-1120]$ & 0.196 \\
\hline CRP mg/l, median [IQR] & $84.1[34-151.1]$ & $131[63.3-201]$ & $<0.001$ & $120[62-192.7]$ & $131[63.3-201]$ & 0.477 \\
\hline LDH U/l, median [IQR] & $344[262-460.4]$ & 382.5 [306-499] & $<0.001$ & $393[290-530]$ & 382.5 [306-499] & 0.797 \\
\hline Ferritin mcg/l, median [IQR] & $857.4[395.9-1596]$ & $\begin{array}{l}1120.7[636.2- \\
1830.9]\end{array}$ & $<0.001$ & $\begin{array}{l}1127.6[528- \\
1990.8]^{[5-}\end{array}$ & $\begin{array}{l}1120.7[636.2- \\
1830.9]^{[6 .}\end{array}$ & 0.855 \\
\hline D-Dimer ng/ml, median [IQR] & $\begin{array}{l}869.5[465.3- \\
1992.8]\end{array}$ & $717[400-1421.3]$ & $<0.001$ & $842[487-1702]$ & 717 [400-1421.3] & 0.003 \\
\hline
\end{tabular}

CRP C-reactive protein, LDH lactate dehydrogenase, IQR interquartile range, CS corticosteroids, CS + TCZ corticosteroids + tocilizumab

COVID-19 Registry. The characteristics of the patients included in this registry have been extensively described previously. ${ }^{19}$ This is a multicenter, nationwide registry with over 150 hospitals. All included patients were diagnosed by polymerase chain reaction (PCR) test taken from a nasopharyngeal sample, sputum, or bronchoalveolar lavage. The collection of data from each patient in terms of laboratory data, treatments, and outcomes was verified by the principal investigator of each center through the review of clinical records.

All participating centers in the register received approval from the relevant Ethics Committees, including Bellvitge University Hospital (PR 128/20).

\section{Inclusion Criteria}

The group that received only CS was considered the standard of care (SOC) for hospitalized patients. We included patients whose CS use started within the first $72 \mathrm{~h}$ after hospital admission and before the onset of high-flow nasal cannula (HFNC), non-invasive mechanical ventilation (NIMV), invasive mechanical ventilation (IMV), or the requirement of intensive care unit (ICU) admission. The CS plus TCZ group included patients who received both drugs in the first $72 \mathrm{~h}$ after hospital admission and also before the onset of HFNC, NIMV, IMV, or ICU admission.

\section{Exclusion Criteria}

We excluded patients who did not receive CS, or received it more than 3 days after hospitalization, those with a nosocomial infection, and those who died within $24 \mathrm{~h}$.

\section{Treatments Prescribed and Definitions of Groups}

We divided the cohort into 2 groups: patients who received solely $\mathrm{CS}$, and patients who received both $\mathrm{CS}$ and TCZ. The usual dose of TCZ in our country was 4$8 \mathrm{mg} / \mathrm{kg}$ iv, generally in a single dose, although some additional doses are allowed at the discretion of the responsible physician.

Regarding antiviral treatment, the use of antivirals (lopinavir/ritonavir, ${ }^{20}$ remdesivir $^{21}$ ), hydroxychloroquine, ${ }^{22}$ and azithromycin ${ }^{22}$ was allowed according to the recommendations of the Spanish Ministry of Health.

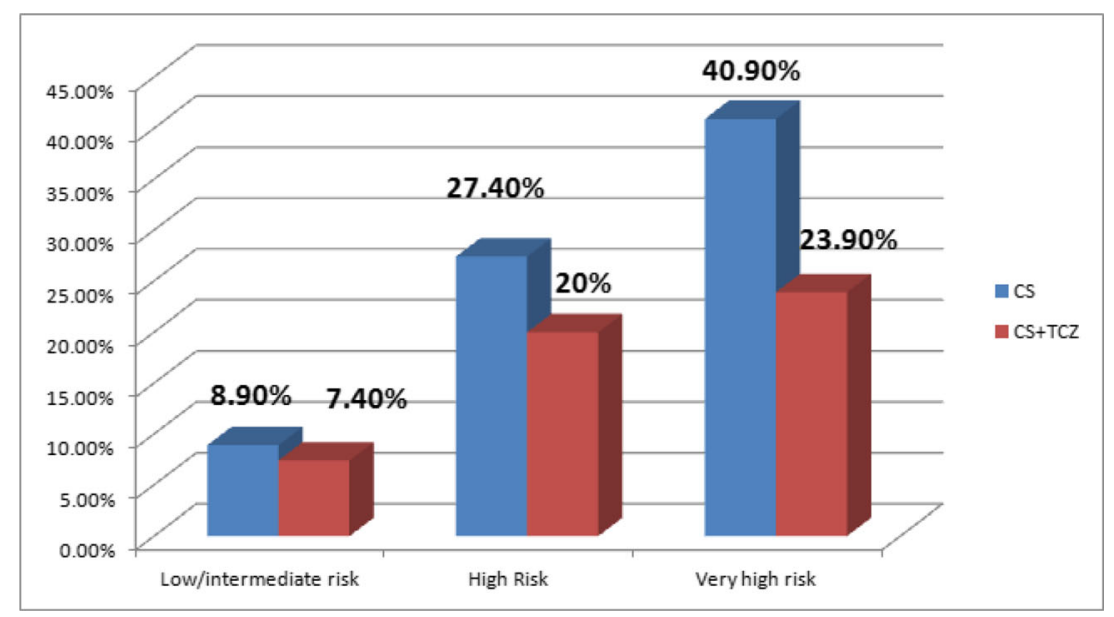

Fig. 2 In-hospital mortality (\%) between groups in the general cohort. 


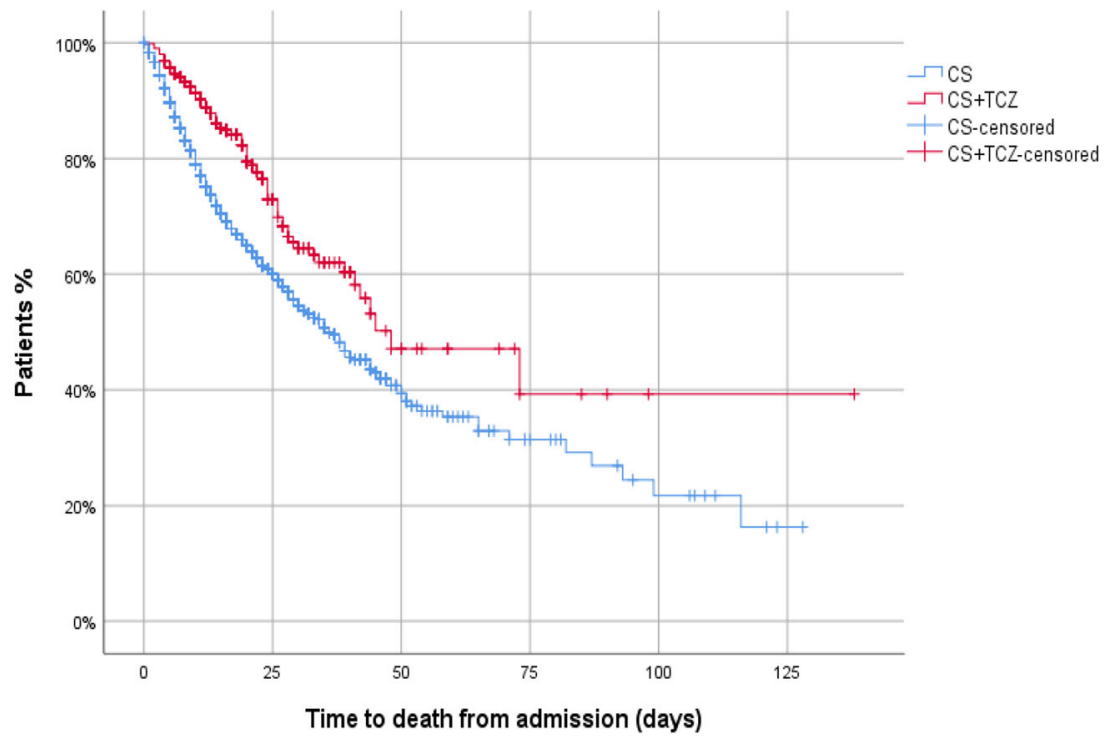

Fig. 3 In-hospital mortality $(\%)$ between groups. Kaplan-Meier. Log-rank test=44.3; $p<0.001$.

\section{Degrees of Inflammation}

We previously reported the 3 categories of risk: (low, intermediate, and high risk) based on the total lymphocyte count, and the C-reactive protein (CRP), lactate dehydrogenase (LDH), ferritin, and D-dimer values taken at the time of admission (Table S1). ${ }^{18}$ The high-risk category was defined based on only 1 of the 5 criteria described above the previously defined cutoff. In addition, for the present study, a very high-risk category was added, defined as the presence of 3 or more high-risk upon admission criteria (Table S1).

\section{Outcome Definition}

The primary outcome of our study was in-hospital mortality. Secondary outcomes included length of stay (LOS), and the requirement of HFNC, NIMV, IMV, and ICU admission.

\section{Statistical Analysis}

Categorical variables were expressed as absolute numbers and percentages. Continuous variables are expressed as mean plus standard deviation (SD) in the case of parametric distribution or median $[\mathrm{IQR}]$ in the case of non-parametric distribution.
Differences among groups were assessed using the chi-square test for categorical variables and the $t$-test or Mann-Whitney test as appropriate for continuous variables. $p$ values $<0.05$ indicated statistical significance.

For the study of risk factors associated with in-hospital mortality, univariate and multivariate binary logistic regression was performed. For the latter, variables with $p<0.10$ in the univariate study plus age and gender were included. Differences in mortality were shown graphically using Kaplan-Meier curves with their log-rank test (event: death; censored data: hospital discharge). Missing data were treated with multiple imputations. To improve the comparability of the groups, propensity score matching (PSM) was performed. This included age, sex, body mass index (BMI), race, smoking behavior, days from onset to admission, all comorbidities, Charlson index, heart rate on admission, tachypnea on admission, $\mathrm{PaO} 2 / \mathrm{FiO} 2$, lymphocyte count, CRP, LDH, ferritin, D-dimer, remdesivir treatment, and prescription of low-molecular-weight heparins (LMWH) during admission.

Statistical analysis was performed by IBM SPSS Statistics for Windows, Version 26.0. Armonk, NY, USA: IBM Corp.

Table 4 Outcomes in the General Cohort

\begin{tabular}{|c|c|c|c|c|c|c|c|c|c|}
\hline & \multicolumn{3}{|c|}{ Low/Intermediate risk } & \multicolumn{3}{|l|}{ High risk } & \multicolumn{3}{|c|}{ Very high risk } \\
\hline & $\begin{array}{l}\mathrm{CS}, \\
N=951\end{array}$ & $\begin{array}{l}\text { CS+TCZ, } \\
N=54\end{array}$ & $\begin{array}{l}p \\
\text { value }\end{array}$ & $\begin{array}{l}\text { CS, } \\
N=4381\end{array}$ & $\begin{array}{l}\text { CS+TCZ, } \\
N=554\end{array}$ & $\begin{array}{l}p \\
\text { value }\end{array}$ & $\begin{array}{l}\mathrm{CS}, \\
N=1542\end{array}$ & $\begin{array}{l}\text { CS+TCZ, } \\
N=238\end{array}$ & $\begin{array}{l}p \\
\text { value }\end{array}$ \\
\hline In-hospital death & $85(8.9)$ & $4(7.4)$ & 1.000 & $\begin{array}{l}1201 \\
(27.4)\end{array}$ & $13(20)$ & $<0.001$ & $630(40.9)$ & $57(23.9)$ & $<0.001$ \\
\hline HFNC & $59(6.2)$ & $16(29.6)$ & $<0.001$ & $452(10.4)$ & $156(28.3)$ & $<0.001$ & $192(12.5)$ & $74(31.2)$ & $<0.001$ \\
\hline NIMV & $32(3.4)$ & $10(18.5)$ & $<0.001$ & $266(6.1)$ & $103(18.6)$ & $<0.001$ & $130(8.4)$ & 39 (16.4) & $<0.001$ \\
\hline IMV & $30(3.2)$ & $9(16.7)$ & $<0.001$ & $268(6.1)$ & $123(22.2)$ & $<0.001$ & $149(9.7)$ & $68(28.6)$ & $<0.001$ \\
\hline ICU & 47 (4.9) & $11(20.4)$ & $<0.001$ & $375(8.6)$ & $168(30.3)$ & $<0.001$ & $188(12.2)$ & $84(35.3)$ & $<0.001$ \\
\hline $\begin{array}{l}\text { Length of stay (days), } \\
\text { median [IQR] }\end{array}$ & $8[5-12]$ & $12[8-18.5]$ & $<0.001$ & $9[6-13]$ & $14[10-20]$ & $<0.001$ & $9[5-14]$ & 15 [10-23] & $<0.001$ \\
\hline
\end{tabular}

HFNC high-flow nasal cannula, NIMV non-invasive mechanical ventilation, IMV invasive mechanical ventilation, ICU intensive care unit, IQR interquartile range, CS corticosteroids, CS+TCZ corticosteroids + tocilizumab 
Table 5 Outcomes in the Matched-Cohort

\begin{tabular}{|c|c|c|c|c|c|c|c|c|c|}
\hline & \multicolumn{3}{|c|}{ Low/Intermediate risk } & \multicolumn{3}{|l|}{ High risk } & \multicolumn{3}{|c|}{ Very high risk } \\
\hline & $\begin{array}{l}\mathrm{CS}, \\
N=65\end{array}$ & $\begin{array}{l}\text { CS+TCZ, } \\
N=54\end{array}$ & $\begin{array}{l}p \\
\text { value }\end{array}$ & $\begin{array}{l}\mathrm{CS}, \\
N=542\end{array}$ & $\begin{array}{l}\text { CS+TCZ, } \\
N=554\end{array}$ & $\begin{array}{l}p \\
\text { value }\end{array}$ & $\begin{array}{l}\mathrm{CS}, \\
N=257\end{array}$ & $\begin{array}{l}\text { CS+TCZ, } \\
N=\mathbf{2 3 8}\end{array}$ & $\begin{array}{l}p \\
\text { value }\end{array}$ \\
\hline In-hospital death & $1(1.5)$ & $4(7.4)$ & 0.175 & $\begin{array}{l}125 \\
(23.1)\end{array}$ & $111(20)$ & 0.223 & $82(31.9)$ & $57(23.9)$ & 0.049 \\
\hline HFNC & $3(4.6)$ & $16(29.6)$ & $<0.001$ & $87(16.1)$ & $156(28.2)$ & $<0.001$ & $50(19.5)$ & 74 (31.1) & 0.003 \\
\hline NIMV & $1(1.5)$ & $10(18.5)$ & 0.002 & $57(10.5)$ & 103 (18.6) & $<0.001$ & $34(13.2)$ & 39 (16.4) & 0.322 \\
\hline IMV & $2(3.1)$ & $9(16.7)$ & 0.022 & 75 (13.8) & $123(22.2)$ & $<0.001$ & $46(17.9)$ & $68(28.6)$ & 0.005 \\
\hline $\mathrm{ICU}$ & $4(6.2)$ & $11(20.4)$ & 0.026 & $\begin{array}{l}102 \\
(18.8)\end{array}$ & $168(30.3)$ & $<0.001$ & $59(23)$ & $84(35.3)$ & 0.002 \\
\hline $\begin{array}{l}\text { Length of stay (days), } \\
\text { median [IQR] }\end{array}$ & $\begin{array}{l}8[4.5- \\
12]\end{array}$ & $12[8-18.5]$ & 0.001 & $\begin{array}{l}10[6.8- \\
16]\end{array}$ & $14[10-20]$ & $<0.001$ & $\begin{array}{l}11[6- \\
20]\end{array}$ & $15[10-23]$ & $<0.001$ \\
\hline
\end{tabular}

HFNC high-flow nasal cannula, NIMV non-invasive mechanical ventilation, IMV invasive mechanical ventilation, ICU intensive care unit, IQR interquartile range, CS corticosteroids, CS+TCZ corticosteroids + tocilizumab

\section{RESULTS}

\section{General Data and Symptoms Between Groups}

A total of 21,962 patients were included in the Registry by May 2021; 9430 were treated with CS or CS plus TCZ and 5940 met our inclusion criteria (5332 were treated with CS and 608 with CS plus TCZ) (Fig. 1). Table 1 shows the differences between the two groups. Those in the isolated CS group were older (72.4 vs. 63.6 years), with less male predominance (58.9\% vs. $72.9 \%)$, higher prevalence of Caucasian population (90.8\% vs. $82.1 \%$ ), higher degree of dependency (21.8\% vs. 4 . $7 \%$ ), hypertension ( $57.8 \%$ vs. $48.8 \%$ ), chronic heart failure (42.3\% vs. $38.5 \%)$, chronic renal failure $(7.7 \%$ vs. $1.1 \%)$, dementia ( $11.3 \%$ vs. $1.8 \%)$, chronic obstructive pulmonary disease (COPD) (9.8\% vs. $6.4 \%)$, and a higher Charlson index (1 vs. 0). The groups were similar after propensity score matching (Table 1).

The CS group presented less frequently (Table 2) with cough (69\% vs. $79.8 \%$ ), arthromyalgia (26.7\% vs. $34.7 \%)$, sore throat ( $8 \%$ vs. $11.8 \%$ ), headache $(11.4 \%$ vs. $15.8 \%)$, fever $(77.2 \%$ vs. 86$)$, and diarrhea $(23.1 \%$ vs. $29.8 \%)$. There were also differences in heart rate ( 87 vs. $91 \mathrm{bpm})$ and tachypnea $(39.6 \%$ vs. $53.9 \%)$.

\section{Lab Tests Between Groups}

The CS group had higher $\mathrm{PaO} 2 / \mathrm{FiO} 2$ (285.7 vs. 271), lymphocytes $\left(900 \times 10^{6}\right.$ vs. $\left.820 \times 10^{6}\right)$, and D-dimer $(869.5$ $\mathrm{ng} / \mathrm{ml} \mathrm{vs.} 717 \mathrm{ng} / \mathrm{ml}$ ) at admission. Alternatively, they had lower CRP (84.1 mg/1 vs. $131 \mathrm{mg} / \mathrm{l})$, LDH (344 U/1 vs. $382.5 \mathrm{U} / \mathrm{l})$, and ferritin $(857.4 \mathrm{mcg} / 1 \mathrm{vs} .1120 .7 \mathrm{mcg} / \mathrm{l})$ (Table 3). These differences disappeared after PSM except for D-dimer, which remained higher in the CS group (842 ng/ml vs. $717 \mathrm{ng} / \mathrm{ml})$.

\section{Treatments Between Groups}

The treatments received in both groups are shown in Table S2. The CS group less frequently received remdesivir $(9.8 \%$ vs. $14.3 \%)$ as well as intermediate $(12.2 \%$ vs. $22.5 \%)$ or full doses of LMWH (14.3\% vs. 22.2\%). These differences disappeared after PSM.
The CS regimen was not standard in all patients. There were significant differences between both groups in the maximum dose of prednisone or equivalent ( $75 \mathrm{mg}$ vs. $100 \mathrm{mg}$ ), days of treatment (7 days vs. 8 days), and cumulative dose (400 mg vs. $600 \mathrm{mg}$ ).

\section{Outcomes Between Groups}

Compared to patients receiving CS alone, in-hospital mortality was significantly lower for combination of CS + TCZ for high risk $(27.4 \%$ vs. $20 \%, p<0.001)$ and very high-risk patients (40.9\% vs. $23.9 \%, p<0.001)$ (Figs. 2 and 3). There was no difference for those with low/intermediate risk $(8.9 \%$ vs. 7.4\%, $p=1.000$ ) (Table 4, Figs. 2 and 3). Our PSM analysis found significantly lower mortality only in the very high-risk category (31.9\%, vs. $23.9 \%, p=0.049)$ (Table 5; Figure S1). After PSM, we found no differences in the low/intermediaterisk $(1.5 \%$ vs. $7.4 \%, p=0.175)$ or the high-risk category (23.1\% vs. $20 \%, p=0.223$ ).

HFNC use was lower in CS patients in all 3 risk categories: $6.2 \%$ vs. $29.6 \%(p<0.001)$ for the low/intermediate-risk category, $10.4 \%$ vs. $28.3 \%(p<0.001)$ for the high-risk category, and $12.5 \%$ vs. $31.2 \%(p<0.001)$ for the very high-risk category (Table 4). After PSM, we found the same differences between groups in the 3 risk categories: $4.6 \%$ vs. $29.6 \%$ $(p<0.001), 16.1 \%$ vs. $28.2 \%(p<0.001)$, and $19.5 \%$ vs. $31.1 \%(p=0.003)$ (Table 5).

NIMV use was also lower in CS patients in all 3 risk categories: $3.4 \%$ vs. $18.5 \%(p<0.001)$ for the low/intermediate-risk category, $6.1 \%$ vs. $18.6 \%(p<0.001)$ for the high-risk category, and $8.4 \%$ vs. $16.4 \%(p<0.001)$ for the very high-risk category (Table 4). After PSM, we found similar differences between groups in the 3 risk categories: $1.5 \%$ vs. $18.5 \%(p<0.001)$, $10.5 \%$ vs. $18.6 \%(p<0.001)$, and $13.2 \%$ vs. $16.4 \%(p=0.322)$.

The use of IMV was also lower in CS patients in all 3 risk categories: $3.2 \%$ vs. $16.7 \%(p<0.001)$ for the low/ intermediate-risk category, $6.1 \%$ vs. $22.2 \%(p<0.001)$ for the high-risk category, and $9.7 \%$ vs. $28.6 \%(p<0.001)$ for the very high-risk category (Table 4). After PSM, we found similar differences between groups in the 3 risk categories: $3.1 \%$ vs. $16.7 \%(p<0.001), 13.8 \%$ vs. $22.2 \%(p<0.001)$, and $17.9 \%$ vs. $28.6 \%(p=0.005)$ (Table 5). 
Table 6 Risk Factors in the Matched-Cohort. High-Risk Category

\begin{tabular}{|c|c|c|c|c|}
\hline & \multicolumn{2}{|l|}{ Univariate analysis } & \multicolumn{2}{|c|}{ Multivariate analysis } \\
\hline & OR $(95 \%$ CI $)$ & $p$ value & OR $(95 \%$ CI $)$ & $p$ value \\
\hline Age & $1.07(1.05-1.09)$ & $<0.001$ & $1.08(1.06-1.09)$ & $<0.001$ \\
\hline Gender (female) & $1.16(0.74-1.81)$ & 0.525 & $0.69(0.47-0.99)$ & 0.045 \\
\hline BMI & $1.02(0.98-1.06)$ & 0.405 & & \\
\hline Race & & & NS & \\
\hline Caucasian (ref.) & 1 ref. & & & \\
\hline Black & $1.10(0.90-1.15)$ & 0.999 & & \\
\hline Hispanic & $0.46(0.21-1.01)$ & 0.054 & & \\
\hline Asian & $2.37(0.15-38.14)$ & 0.543 & & \\
\hline Others & $0.79(0.16-3.96)$ & 0.774 & & \\
\hline Moderate/severe dependency & $4.90(2.77-8.68)$ & $<0.001$ & $1.98(1.01-3.90)$ & 0.048 \\
\hline Arterial hypertension & $2.33(1.55-3.49)$ & $<0.001$ & NS & \\
\hline Dyslipidemia & $1.75(1.18-2.59)$ & 0.006 & NS & \\
\hline Diabetes mellitus & $1.81(1.15-2.83)$ & 0.010 & NS & \\
\hline Ischaemic cardiopathy & $2.06(1.08-3.93)$ & 0.028 & NS & \\
\hline Chronic heart failure & $7.59(2.90-19.83)$ & $<0.001$ & NS & \\
\hline Chronic liver disease & $1.10(0.42-2.93)$ & 0.845 & & \\
\hline Severe chronic renal failure & 4.04 (1.41-11.57) & 0.009 & NS & \\
\hline Dementia & $5.24(0.95-28.97)$ & 0.057 & NS & \\
\hline Cancer & $2.54(1.41-4.59)$ & 0.002 & NS & \\
\hline COPD & $2.49(1.11-5.61)$ & 0.027 & NS & \\
\hline Asthma & $0.58(0.25-1.34)$ & 0.202 & & \\
\hline OSAS & $1.67(0.80-3.39)$ & 0.176 & & \\
\hline Charlson index & $1.28(1.15-1.43)$ & $<0.001$ & $1.14(1.04-1.24)$ & 0.003 \\
\hline Respiratory rate $>20 \mathrm{rpm}$ & $2.29(1.49-3.54)$ & $<0.001$ & $2.01(1.41-2.87)$ & $<0.001$ \\
\hline $\mathrm{PaO} 2 / \mathrm{FiO} 2$ & $0.99(0.99-0.99)$ & $<0.001$ & $0.99(0.99-0.99)$ & $<0.001$ \\
\hline Tocilizumab & $0.67(0.45-0.99)$ & 0.050 & $0.78(0.56-1.09)$ & 0.150 \\
\hline
\end{tabular}

BMI body mass index, NS not significant, COPD chronic obstructive pulmonary disease, OSAS obstructive sleep apnea syndrome

The need for ICU admission was lower in patients with CS in all 3 risk categories: $4.9 \%$ vs. $20.4 \%(p<0.001)$ for the low/intermediate-risk category, $8.6 \%$ vs. $30.3 \%$ $(p<0.001)$ for the high-risk category, and $12.2 \%$ vs. $35.3 \%(p<0.001)$ for the very high-risk category (Table 4). After PSM, we found similar differences between groups in the 3 risk categories: $6.2 \%$ vs. $20.4 \%$ $(p<0.001), 18.8 \%$ vs. $30.3 \%(p<0.001)$, and $23 \%$ vs. $35.3 \%(p=0.002)$ (Table 5).

Finally, median LOS was higher in patients with CS+TCZ in all 3 risk categories: 8 days vs. $12(p<0.001)$ for the low/ intermediate-risk category, 9 days vs. $14(p<0.001)$ for the high-risk category, and 9 days vs. $15(p<0.001)$ for the very high-risk category (Table 4). After PSM, we found similar differences between groups in the 3 risk categories: 8 days vs. $12(p=0.001), 10$ days vs. $14(p<0.001)$, and 11 days vs. 15 $(p<0.001)$ (Table 5).

\section{Risk Factors for In-Hospital Mortality}

The independent risk factors for mortality in the highrisk category were age, male sex, moderate/severe dependency, higher Charlson index, tachypnea on admission, and lower $\mathrm{PaO} 2 / \mathrm{FiO} 2$ (Table 6). The use of TCZ showed a trend of benefit that did not reach statistical significance as an independent protective factor. The very high-risk category showed similar results (data not shown). The AUC of the final model was 0.792 (Figure S2).

\section{DISCUSSION}

We found that higher degrees of inflammation responded to combination therapy, consistent with COVID-19 as an inflammatory disease. Treatment should be risk-stratified based on inflammation. At present, the approach to the disease has been heterogeneous and often based on oxygenation/ventilation status. In order to evaluate the efficacy of immunosuppressive/ anti-inflammatory treatments, we have to include the degree of inflammation in patients to judge efficacy. The degree of inflammation in most studies is difficult to assess and appears to include many patients with low degrees of inflammation. It is thus difficult to know the real efficacy of these drugs and explain differences in efficacy between observational studies and clinical trials [23].

Our results suggest that the greater the inflammation, the more effective these drugs will be. Our group previously described 3 categories of inflammation based on 5 parameters at admission (lymphopenia, CRP, LDH, ferritin, and D-dimer). ${ }^{18}$ Since the low-risk category rarely requires hospital admission, it is the least numerous in our national series.

Our study shows that the addition of TCZ does not provide benefit in the low/intermediate-risk category. While the combination reduced mortality in the high-risk group, we did not achieve statistical significance, due to inadequate power. Patients classified as very high risk (3-5 high-risk criteria) had statistically significant reduction in death.

Our secondary outcomes (use of HFNC, NIMV, and IMV, and admission to the ICU) suggest that the CS+TCZ group 
had more severe disease despite PSM. The sociodemographic, clinical, and analytical data included could not fully capture patient severity. Our patients were on oxygen therapy (not high-flow) at the time of treatment initiation (CS patients or $\mathrm{CS}+\mathrm{TCZ}$ patients). However, we do not know the exact FiO2 they were receiving; it is possible that the combination of $\mathrm{CS}+\mathrm{TCZ}$ was used in patients requiring higher amounts of oxygen.

Our study strengths include that it is large and nationally representative. In addition, the therapeutic approach based on degree of inflammation is a good approximation to clinical practice decision-making.

Our study also has some limitations. First, it is a retrospective study. Second, it comes from a multicenter registry, with the heterogeneity that this implies, though we used standardized definitions. Another limitation to be taken into account is the heterogeneity in CS dosage and administration time as well as lack of information of important variables that might trigger addition of TCZ, such as oxygen requirement.

In conclusion, the prescription of $\mathrm{CS}$ alone or in combination with TCZ should be based on the degrees of inflammation and reserve the CS plus TCZ combination for patients at high and especially very high risk.

Supplementary Information The online version contains supplementary material available at https://doi.org/10.1007/s11606-02107146-0.

Acknowledgements: We gratefully acknowledge all the investigators who participated in the SEMI-COVID-19 Registry. We also thank the SEMI-COVID-19 Registry Coordinating Center for their quality control data, logistic, and administrative support.

Corresponding Author: Manuel Rubio-Rivas, $M D \mathrm{PhD}$; Department of Internal Medicine, Bellvitge University Hospital, Bellvitge Biomedical Research Institute-IDIBELL, University of Barcelona, Barcelona, Spain (e-mail: mrubio@bellvitgehospital.cat).

\section{Declarations:}

Conflict of Interest: The authors declare that they do not have a conflict of interest.

\section{REFERENCES}

1. Hu B, Huang S, Yin L. The Cytokine Storm and COVID-19. J Med Virol 2020. https://doi.org/10.1002/jmv.26232. Online ahead of print.

2. RECOVERY Collaborative Group, Horby P, Lim wS, Emberson JR, et al. Dexamethasone in hospitalized patients with COVID-19. N Engl J Med. 2021; 384: 693-704.

3. Rubio-Rivas M, Ronda M, Padulles A, et al. Beneficial effect of corticosteroids in preventing mortality in patients receiving tocilizumab to treat severe COVID-19 illness. Int J Infect Dis. 2020; 101: 290-7.

4. Stone JH, Frigault MJ, Serling-Boyd NJ, et al. Efficacy of tocilizumab in patients hospitalized with COVID-19. N Engl J Med 2020; 383: 233344.
5. Salvarani C, Dolci G, Massari M, et al. Effect of tocilizumab vs standard care on clinical worsening in patients hospitalized with COVID-19 pneumonia. A randomized clinical trial. JAMA Intern Med 2021; 181: 24-31.

6. Hermine $\mathbf{O}$, Mariette $\mathbf{X}$, Tharaux PL, Resche-Rigon M, Porcher R, Ravaud P. Effect of tocilizumab vs usual care in adults hospitalized with COVID-19 and moderate or severe pneumonia. A randomized clinical trial. JAMA Intern Med 2021; 181: 32-40.

7. Malekzadeh R, Abedini A, Mohsenpour B, et al. Subcutaneous tocilizumab in adults with severe and critical COVID-19: a prospective open-label uncontrolled multicenter trial. Int Immunopharmacol. 2020; 89: 107102 .

8. Dastan F, Saffaei A, Haseli S, et al. Promising effects of tocilizumab in COVID-19: a non-controlled, prospective clinical trial. Int Immunopharmacol. 2020; 88: 106869.

9. Salama C, Han J, Yau L, et al. Tocilizumab in patients hospitalized with COVID-19 Pneumonia. N Engl J Med. 2021; 384: 20-30.

10. Veiga VC, Prats JAGG, Farias DLC, et al. Effect of tocilizumab on clinical outcomes at 15 days in patients with severe or critical coronavirus disease 2019: randomised controlled trial. BMJ. 2021; 372: n84.

11. Pomponio G, Ferrarini A, Bonifazi M, et al. Tocilizumab in COVID-19 interstitial pneumonia. J Intern Med. 2021: https://doi.org/10.1111/ joim. 13231.

12. Perrone F, Piccirillo MC, Ascierto PA, et al. Tocilizumab for patients with COVID-19 pneumonia. The single-arm TOCIVID-19 prospective trial. J Transl Med. 2020; 18: 405.

13. REMAP-CAP Investigators, Gordon AC, Mouncey PR, Al-Beidh F, et al. Interleukin-6 receptor antagonists in critically ill patients with COVID-19. N Engl J Med. 2021:NEJMoa2100433.

14. Rosas IO, Bräu N, Waters M, et al. Tocilizumab in hospitalized patients with severe COVID-19 pneumonia. N Engl J Med. 2021 Feb 25:NEJMoa2028700.

15. Soin AS, Kumar K, Choudhary NS, et al. Tocilizumab plus standard care versus standard care in patients in India with moderate to severe COVID-19-associated cytokine release syndrome (COVINTOC): an openlabel, multicentre, randomised, controlled, phase 3 trial. Lancet Respir Med. 2021: S2213-2600(21)00081-3.

16. Wang $\mathbf{D}$, Fu B, Peng $\mathbf{Z}$, et al. Tocilizumab in patients with moderate or severe COVID-19: a randomized, controlled, open-label, multicenter trial. Front Med. 2021: 1-9.

17. RECOVERY Collaborative Group. Tocilizumab in patients admitted to hospital with COVID-19 (RECOVERY): a randomised, controlled, openlabel, platform trial. Lancet. 2021;397(10285):1637-45.

18. Rubio-Rivas M, Corbella X, Formiga F, et al. Risk categories in COVID19 based on degrees of inflammation. Data on more than 17,000 patients from the Spanish SEMI-COVID-19 registry. J Clin Med 2021.

19. Casas-Rojo JM, Antón-Santos JM, Millán-Núñez-Cortés J, et al. Clinical characteristics of patients hospitalized with COVID-19 in Spain: results from the SEMI-COVID-19 Registry. Rev Clin Esp. 2020;220(8):480-494.

20. Lora-Tamayo J, Maestro G, Lalueza A, et al. Early lopinavir/ritonavir does not reduce mortality in COVID-19 patients: results of a large multicenter study. J Infect. $2021 \mathrm{Feb}$ 11:S0163-4453(21)00077-3.

21. Beigel JH, Tomashek KM, Dodd LE, et al. Remdesivir for the treatment of COVID-19 - final report. N Engl J Med. 2020;383(19):1813-1826.

22. Gautret P, Hoang VT, Lagier JC, Raoult D. Effect of hydroxychloroquine and azithromycin as a treatment of COVID-19: results of an open-label non-randomized clinical trial, an update with an intention-to-treat analysis and clinical outcomes. Int $\mathrm{J}$ Antimicrob Agents. 2021;57(1): 106239 .

23. Tleyjeh IM, Kashour Z, Riaz M, Hassett L, Veiga VC, Kashour T. Efficacy and safety of tocilizumab in COVID-19 patients: a living systematic review and meta-analysis-first update. Clin Microbiol Infect. 2021 Apr 27:S1198-743X(21)00204-4.

Publisher's Note: Springer Nature remains neutral with regard to jurisdictional claims in published maps and institutional affiliations. 